\title{
Letters
}

\section{Open letter to Tony Blair: Call to prevent escalating violence}

EdiToR-Three important reports have been published in the past month on the humanitarian impacts of international violence and conflict. ${ }^{1-3}$ All provide evidence of the short and long term adverse health impacts of the use of force internationally. The World Health Organization's World Report on Violence and Health is a detailed assessment compiled over three years by international health scientists. ${ }^{1}$ Collateral Damage: The Health and Environmental Costs of War on Iraq is a report of a study by Medact, a UK charity of nurses, doctors, and other health professionals. ${ }^{2}$ The latest report released by the Campaign Against Sanctions on Iraq (CASI) based at Cambridge University, is a UN report on likely humanitarian scenarios of war on Iraq. ${ }^{3}$

Medact estimates that if the threatened war on Iraq ensues, "total possible deaths on all sides during conflict and in the following three months will range from 48000 to over 260000 . Civil war within Iraq could add another 20000 deaths. Additional later deaths from postwar adverse health effects could reach 200000 . In all scenarios the majority of casualties will be civilians." The report calculates that "the aftermath of a 'conventional' war could include civil war, famine and epidemics, refugees and displaced people, and catastrophic effects on children's health and development." Knock-on effects could include exacerbation of international conflicts, inequalities, and divisions.

The most recent UN report also estimates substantial and wide-reaching humanitarian impacts: "As many as 500000 people could require treatment to a greater or lesser degree as a result of direct or indirect injuries," on the basis of the WHO's estimates of 100000 direct and 400000 indirect casualties. It indicates existing shortages of some medical items, "rendering the existing stocks inadequate" for war increased demand, and exacerbated by the "likely absence of a functioning primary health care system in a post-conflict situation."

The report also "estimated that the nutritional status of some 3.03 million people countrywide will be dire and that they will require therapeutic feeding [according to Unicef's estimates]." Finally, "it is estimated that there will eventually be

The names of the 500 signatories to this letter are published on bmj.com. some 900000 Iraqi refugees requiring assistance, of whom 100000 will be in need of immediate assistance [according to the United Nations High Commissioner for Refugees (UNHCR)] ... An estimated 2 million people will require some assistance with shelter." For 130000 existing refugees in Iraq "it is probable that UNHCR will initially be unable to provide the support required."

But the most worrying impact of the use of force in Iraq and internationally is in its role as an escalator of collective violence. The WHO defines "collective violence"-by states or non governmental groups-as: "The instrumental use of violence by people who identify themselves as members of a group-whether this group is transitory or has a more permanent identity-against another group or set of individuals, in order to achieve political, economic or social objectives." The WHO reports that such collective use of force has long term negative impacts on stability and social wellbeing. International violence has been steadily increasing and "overall a total of 72 million people are believed to have lost their lives during the 20th century due to conflict, with an additional 52 million lives lost through genocides." Conflict escalates after use of collective force, as violence becomes a more common and legitimated form of political

Health professionals worldwide care for the casualties of war. We accept this responsibility. However, it is also our responsibility to argue for prevention of violence and peaceful resolution of conflict. Staff and students of the London School of Hygiene and Tropical Medicine come from and work in over 120 countries, many in conflict. Our experience and evidence corroborate the views of the WHO, United Nations, and Medact.

We believe that a war would have disastrous short, medium, and long term social and public health consequences-not just for Iraq, but internationally. Conflict is rooted in inequality and unjust governance. Military intervention in Iraq, when there remain so many peaceful routes to disarmament, risks escalating collective violence. The WHO argues that conflict can be averted only by more equitable forms of development and by accountable, ethical governance internationally. We strongly support this perspective and believe that further acts of violence can be prevented by or social action. international and local governance that shows itself to be peaceful and ethical.

For the reasons above, we oppose the use of military intervention in Iraq. We hope this letter contributes to informed discussion among members of the government and the public. We also intend this statement to support all those who are opposed to military action on ethical and humanitarian grounds, not originating from any political or religious view point.

Carolyn Stephens senior lecturer in environment and health policy, department of public health and polic London School of Hygiene and Tropical Medicine, London WC1E 7HT

carolyn.stephens@lshtm.ac.uk

On behalf of the staff, students, and alumni of the London School of Hygiene and Tropical Medicine, and in collaboration with Medact.

1 World Health Organization. World report on violence and health. Available at www.who.int/violence injury prevention/main.cfm? $\mathrm{p}=0000000682$ (accessed $20 \mathrm{Jan}$ 2003).

2 Medact. Collateral damage: the health and environmental costs of war on Iraq. Available at: www.medact.org/tbx/ pages/sub.cfm?id=556 (accessed 20 Jan 2003).

3 Campaign Against Sanctions on Iraq (CASI). Internal UN report. Likely humanitarian scenarios. Available at: report. Likely humanitarian scenarios. Available at:
www.casi.org.uk/info/undocs/war021210.pdf (accessed 20 Jan 2003).

\section{Doctors and computers}

See also p 202

Poor system design and little investment mean hospital doctors do not use computers ...

EDITOR-Benson's article neatly summarises some of the difficulties hospital doctors have using computers. ${ }^{1}$ I would enthusiastically use computers in hospitals if seven points applied.

(1) Computers were readily available.

(2) Security measures were sensible.

(3) Email could be picked up both in the trust and at home or other work places.

(4) Patient details or past letters were accessible so, for example, you could see an emergency referral with some idea of what had previously happened.

(5) Pathology results could be viewed rapidly.

(6) Medical records were readily accessible.

(7) Access to the internet was good enough to allow, for example, reading of medical journals.

These measures would empower doctors and make computers useful. In the trust where I work the IT department has been starved of funds, is several hundred comput- 